the latter is $4^{\circ}$ long, and slender, having a contortion $0.75^{\circ}$ from the nucleus. On September is this contortion was $1^{\circ} 4^{\circ}$ from the head, and the tail, $5^{\frac{1}{4}}$ long, was clearly double $2 \frac{1}{2}^{\circ}$ from the head.

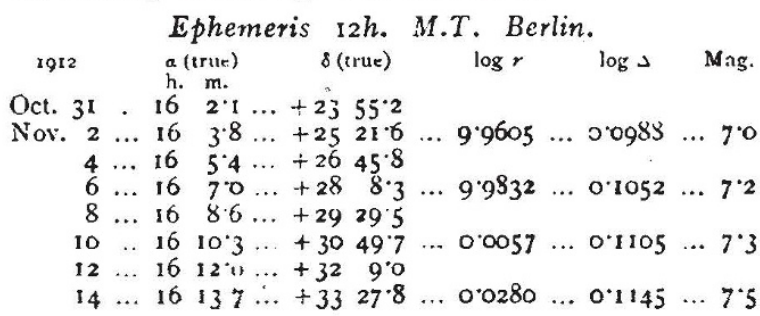

Dr. Ebell calculated the brightness, by the formula $1 / r^{2} \Delta^{2}$, on the assumption that on September 26 the magnitude was 60 , but $\mathrm{Mr}$. Franks found it to be a little more than $4^{\circ}$ o on October ir, while, in a good sky, M. Gonnessiat estimated it as 5.5 for the whole comet, on September 29. There appears to be definite evidence for an intrinsic brightening while near perihelion.

The Total Solar Eclipse of October 10.-A telegram from Prof. Morize to the Astronomische Nachrichten (No, 4606) states that the observations of the total eclipse at Christina (Minas Geraes, Brazil) were spoiled by rain although some selenium-cell observations of brightness were made by Dr. Ristenpart. Prof. Perrine, cabling to Prof. Pickering from Brazil, also states that rain prevented observations. further telegram, published in No. 4 trot of the same journal, announces that the eclipse was observed under favourable conditions at Quito by Señor Tufiño.

International Standard Time.-The Revue générale des Sciences (No. 89 ) gives an outline of the present state of the question of the international standardisation of time, and the programme prepared for discussion at the International Conference which met at the Paris Observatory on October 15. The acceptation by France of the international réseau removed the last great obstacle to the unification of standard times, and the general distribution of time-signals by wireless telegraphy makes this unification more than ever necessary. It has been found that signals sent from different stations show inconsistencies amounting to seyeral seconds, not very serious in ordinary atairs, but fatal in matters demanding scientific precision. To remedy this state of affairs the Bureau des Longitudes invited the International Conference to reassemble in Paris, and drew up a tentative programme of the matters for discussion. Under seven main headings this programme practically exhausts the debatable points concerning the determination of time, the methods of keeping it, and of distributing it by radio-telegraphy and otherwise, the precision necessary for different purposes, and the general question of how to oryanise internationally in order to gain these ends.

\section{THE ORIGIN OF LIFE.}

NE of the most interesting of the recent meetings of the British Association at Dundee was that devoted by the joint sections of Zoology and Botany to the discussion of the problem of the origin of life. It should be remarked that this was not a discussion of the President's address; it was arranged before the subject of the presidential address had been made known. The President (Prof. E. A. Schäfer), who occupied the chair at this meeting, explained at the outset that his address had been written and printed before he knew that this discussion was to take place.
Prof. E. A. Minchin, in opening the discussion, pointed out that the probtem of the origin of life involved two inquiries, both of which were at nresent of a speculative order, namely : (1) the nature and characters of the earliest living beings, and (2) the manner in which the primordial form of life took origin and maintained its existenoc upon the earth. The first of these problems could be considered with profit, but the second, owing to the inadequacy of the data available, appeared to him o be scarcely ripe for discussion. He observed that the cell, which might be defined as an individualised mass of protoplasm containing at least one nucleus, was generally regarded as the simplest type of organism, and as the vital unit in the composition of living beings, whether plants or animals. It was improbable that the earliest forms of life came into existence as organisms cornposed of two distinct structural elements - the nucleus and the cytoplasm (body-protoplasm). Which of these-the cytoplasm or the nucleus-was to be regrarded as representing or containing the most primitive elements of the living substance? By most biologists the cytoplasm had been considered to represent the true living substance, and the earliest living organisms-the sp-called Monera-had been supposed to be formless masses of protoplasm without nuclei.

Prof. Minehin proceeded to advance reasons for believing that the chromatin substance invariably present in the nucleus, or occurring as grains (chromidia) scattered in the cytoplasm, represented the primary and essential living matter. In support of this view he pointed out that chromatin is always present in the bodies of living organisms of all kinds, that cells cannot continue to live if deprived of their nuclei, that in reproduction by fission the chromatin divides first and is distributed among the daughter-individuals, that the complex process of division of the nucleus known as karyokinesis may be regarded as a mechanism gradually evolved and perfected for ensuring an exact quantitative and qualitative partition of the chromatin between the daughter-nuclei-an indication that the chromatin is of prime importance-that the chromatinsubstance plays an essential part in syngamy (fertilisation) and probably also in heredity (as carrier of the characters of the organism), that the nucleus is essential for the continuance of the secretory activities of the cell, and, finally, that in some of the minutest living organisms-e.g. spirochætes and the male gamete of the malaria parasite the body appears to consist mainly or entirely of chromatin, and cytoplasmic elements are reduced to a minimum or are altogether absent. Prof. Minchin quoted from a communication received recently from a correspondent, who pointed out that the protein molecules of the nucleus are simpler in constitution than those of the cytoplasm, and therefore may be regarded as more primitive. Further, the amido-acids characteristic of the nucleus are of the open-chain order and free from complexity, while those of the cytoplasm are of the closed order and could only have arisen from the type of acids present in the nucleus. For these reasons Prof. Minchin regarded the chromatin as the primitive living substance, and held the view that the earliest forms of life were very minute particles of chromatin, round which, in the course of evolution, achromatinic substances were formed. Within the cytoplasmic envelopes thus produced the chromatin-grains increased in number, and organisms of the degree of structural complexity of a true cell arose finally by concentration of the chromatin-grains into a compact organised mass-the nucleus proper.

As regarded the origin of the earliest living beings, it was only possible to frame vague speculations, in the present state of our knowledge, concerming the

No. 2244, vOL. 90] 
chemistry of the protein compounds, on the one hand, and the metabolism and modes of life of the simplest living things on the other. He referred to the extreme view, represented by Arrhenius, that life had had no origin in finite time, but was coeval with matter and energy, and then turned to consider the view, more prevalent among biologists, that living matter had arisen at some time from that which was not living. If life arose under conditions not now cxisting in nature, there seemed to be no reason why such conditions could not be reproduced artificially, but if the conditions under which life arose de novo were not different from those existing there seemed to be no reason why it should not do so again. Why, then, did we not see new forms of life appearing on the earth? Prof. Minchin doubted if the simplest forms of life were yet known, or even if we could recognise them or be aware of their existence at their first appearance. The first origin of life involved a synthesis of protein substances in nature by some process as yet totally unknown. For light on these problems we must look to the future advance of knowledge, and especially of chemical science. In the present state of our knowledge, the attitude towards the problem of the origin of life could only be one of expectancy for more light in the future; at present it was not possible to frame a hypothesis which could have any greater value than that of a pious belief.

Mr. Harold Wager said that the more one saw of the lower forms of life, the more remote seemed to become the possibility of conceiving how life arose. $\mathrm{He}$ opposed Prof. Minchin's view that chromatin was the primary living substance, and in support of his contention referred to the structure of the blue-green algæ. These, he said, were interesting as the only organisms which would survive in very hot water $(e . g$. hot springs), and had been regarded as probably the last remnants of the early vegetation of this earth. Each cell of those algæ contained an irregular network of chromatin without a limiting membrane, and not clearly differentiated from the surrounding protoplasm, i.e. the chromatin more nearly resembled the cytoplasm in these than in higher organisms. Further, in certain bacteria there were granules of nuclear matter, but in others there were none, the organism consist. ing of cytoplasm only. These facts impelled $\mathrm{Mr}$. VVager to regard the cytoplasm, and not the chromatin, as the fundamental life-substance.

Prof. F. W. Keeble thought that, having regard to the highly complex interacting phenomena presented by living organisms, it was improbable that the creation of "synthetic life" would be seen in the near future.

Prof. A. B. Macallum believed, with Tyndall, that matter was endowed with the potentiality of life, and to that extent he was in sympathy with the view of Arrhenius. No doubt the organism which first came into existence was ultra-microscopic, and comprised but a ferw molecules. The conditions necessary to produce such organisms do not now hold, but at one time the earth's surface was a vast laboratory in which syntheses of various kinds took place, and a favourable conjunction of forces produced the combination of a rumber of molecules in which life was. This organism would not be a cell, with cytoplasm and nucleus, but an ultra-microscopic body. The cell was as far removed from such a minute body as man is from the cell.

Prof. Benjamin Moore sald that vitalism was a purely static view of life, and was untenable. Structure was important, but something more than structure was necessary for life; dynamic energy-energy, motion, change-was essential, and was manifest in all living organisms. To suppose that life began as blue-green algæ, or some such complex organism, was nonsensical. It was necessary to begin with the formation of organic molecules from the inorganic, then to build up more complex molecules (in which all the atomic combinations were saturated), and group them into colloidal substances. The colloids, which are large aggregates of molecules, show the properties of dawning life, for in presence of sunlight colloids begin to form organic bodies, but it would be necessary to add to the colloid an energy-transformer. He regarded the problem under discussion not as metaphysical, but experimental.

Prof. J. S. Macdonald regarded the problem from the point of view of a physiologist, and said he could not accept the statement that chromatin was the most important portion of the living cell, for in muscle the contractile mechanism is located in the cytoplasm, the functional activity of a red blood-cell is resident in the cytoplasm, and the main functions of the central nervous system are also associated with the cytoplasm. $\mathrm{He}$ held, therefore, that the nuclear material was not concerned in carrying out the main functions of the body.

Prof. Marcus Hartog referred to the power of multiplication of organisms, and said he could see no reasonable probability of our being able to create life afresh, or, indeed, to understand how it came into existence,

Prof. Patrick Geddes put forward a plea for the psychological aspect of the inquiry, for he held that even the simplest organisms presented a dawn of psycho-biosis, and that life was not merely a question of matter (e.g. chromatin).

Dr. J. S. Haldane said he belonged to a school which believed life could not be explained, or interpreted finally, by the known chemico physical properties of matter, and he could not imagine any taboratory experiment, according to our present knowledge, which would bring us any nearer to the origin of life.

The Rev, T. R. R. Stebbing pointed out that for years past many evolutionists had recognised, as a necessity of the theory, that organic life must have been derived from what was inorganic, and that it was reassuring to find that this a priori speculation could be supported on grounds of scientific probability.

Dr. P. Chalmers Mitchell stated that in his opinion there was not a single property of protoplasm which had not its exact physical parallel, nor a single quality of life which would show there existed in life something which was not to be found in matter.

J. H. A.

\section{THE SCIENTIFIC THEORY AND OUT- STANDING PROBLEMS OF WIRELESS TELEGRAPHY,}

$\mathrm{N}$ opening a discussion on the present state of the theory of wircless telegraphy and its outstanding problems, I am, to some extent, embarrassed by the wide field which presents itself for consideration.

I venture to think that we may best take advantage of the simultaneous presence here of physicists, mathematicians, engineers, and electricians, if we endeavour to focus attention, in the first place, on some of the chief scientific problems which are yet unsolved in connection with it.

Perhaps a word of explanation may be offered on the reason for giving prominence to the scientific aspect of the subject rather than its practical achievements. The achievements loom large in the public eye, and are astonishing to the uninitiated, but experts in radio-telegraphy are well aware that many of the

I Introductorv remarks by Prof. I. A. Fleming, F.R.S., at a joint discussion by Sections $A$ and $G$ of the British Association at Dundee.

No. 2244, vor. 90] 